\title{
La Digitalizadora de la Memoria Colectiva: solo no puedes, con amigos sí
}

\author{
Isabel Medrano Corrales | Asociación de Archiveros de Andalucía \\ Carmen Lampaya Latorre | Asociación Pro Derechos Humanos de Andalucía \\ José Escalante Jiménez | Archivo Histórico Municipal de Antequera \\ Miguel Paredes Arjona | Intermedia Producciones \\ Óscar Clemente Galán | Gea-21
}

URL de la contribución <www.iaph.es/revistaph/index.php/revistaph/article/view/4750>

La Digitalizadora de la Memoria Colectiva es una red formada por profesionales audiovisuales, archiveros/as, de participación ciudadana, colectivos sociales y ciudadanía preocupados por la conservación de la memoria audiovisual de los movimientos sociales.

El proyecto surge de la conciencia del riesgo de desaparición de los documentos audiovisuales generados por los movimientos sociales a partir de los años 70, cuando aparecen los formatos de grabación domésticos (magnetófonos, tomavistas de súper $8 \mathrm{~mm}$ y más tarde vídeo cámaras) y la memoria audiovisual deja de ser un privilegio de las élites. Asociaciones de vecinos, grupos ecologistas, agrupaciones de mujeres, el movimiento LGTB, pacifistas y muchos otros grupos de activistas sociales, comienzan a producir sus primeras obras audiovisuales a partir de esas fechas. En esas cintas, actualmente con problemas de obsolescencia de formatos y caducidad física de los soportes magnéticos, están registrados momentos importantes de los últimos 30 años del siglo XX, a través de la mirada particular de sus creadores.

La red se fundamenta en la colaboración entre agentes de diversos perfiles, privados y públicos, profesionales y voluntarios, para inventar una solución alternativa a la digitalización de conjuntos de documentos audiovisuales por los Archivos públicos, una tarea inviable con los actuales recursos públicos de que disponen. Con este ideal, surge la sinergia entre colectivos sociales, particulares, profesionales de los archivos y de los audiovisuales, en ejercicio y jubilados, personas que desde

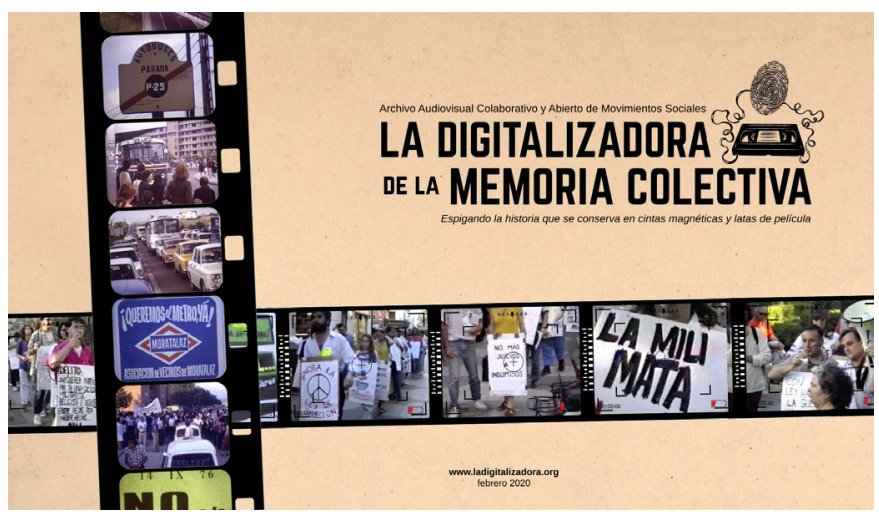

Portada de dossier informativo La Digitalizadora de la Memoria Colectiva

instituciones públicas y privadas se interesan en participar aportando sus saberes y recursos.

La Digitalizadora se concibe como un mediador cultural que promueve una simbiosis con las instituciones dedicadas a la custodia, conservación y difusión de documentos, con el fin de lograr objetivos que no serían asumibles por cualquiera de estas tres partes por separado. La ciudadanía es capaz de localizar colecciones que serían difícilmente accesibles sin su agenda de contactos personales. Los profesionales audiovisuales y de archivo garantizan que los procesos de digitalización y descripción archivística cumplen los estándares de calidad. Las instituciones apoyan con recursos e infraestructuras un proceso participativo que rescata y pone en valor la memoria ciudadana.

Los objetivos de "La Digitalizadora de la Memoria Colectiva" son: 
a debate Hacia una nueva institucionalidad cultural. Modelos emergentes de gestión...

| coordina Jesús Carrillo Castillo

> Localizar documentos audiovisuales y colecciones de movimientos sociales como el vecinal, ecologista, pacifista, feminista... que no estén digitalizados y que presenten riesgos de conservación. Para ello estamos dinamizando una red de colaboradores a los que denominados espigadores, apelando a la figura de aquellas personas que recuperan cosas que los demás dejan atrás, en homenaje a la cineasta francesa Agnès Varda.

> Digitalizar y restaurar los audiovisuales, sin coste para los propietarios, de forma profesional y con máxima calidad.
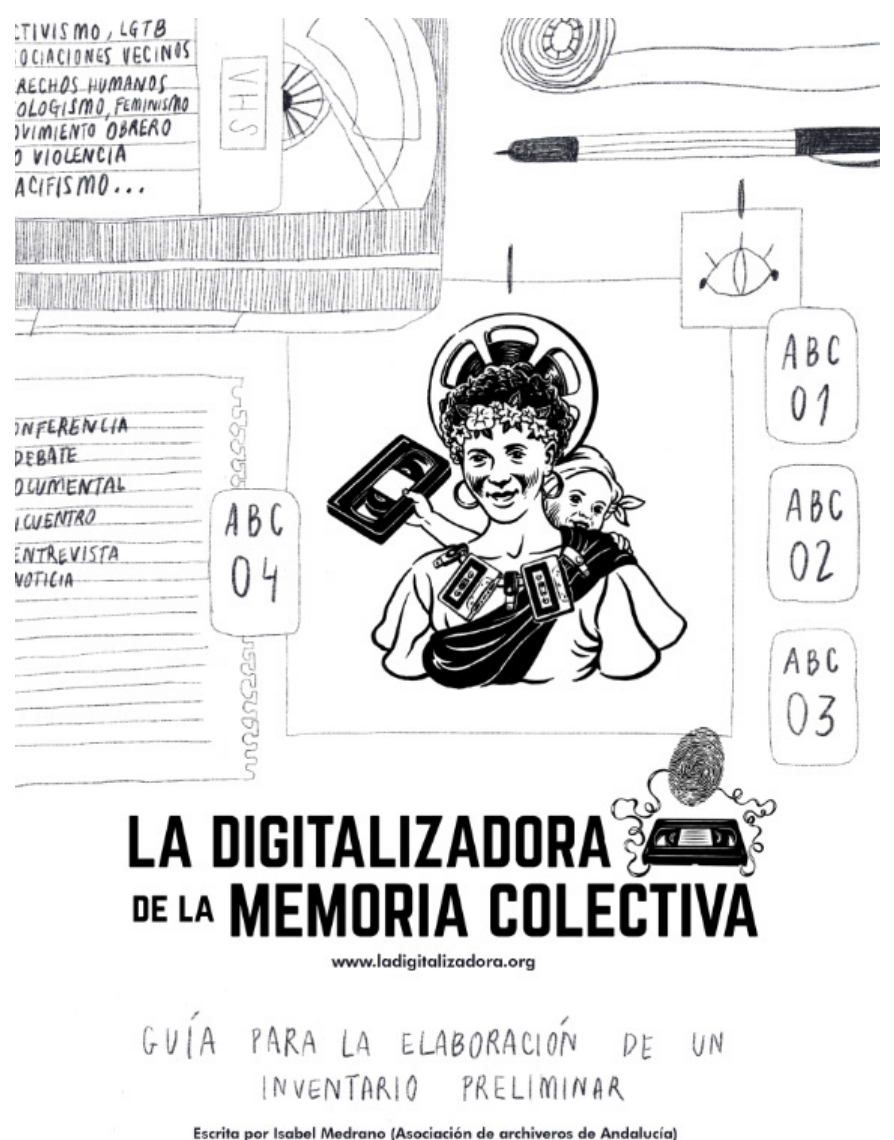

Portada de la Guía para la elaboración de un inventario preliminar. La Digitalizadora de la Memoria Colectiva
$>$ Describir los audiovisuales por sus propios creadores, guiados por archiveros y ofreciéndoles herramientas que cumplan estándares de interoperabilidad.

$>$ Enriquecer los documentos audiovisuales incorporando los testimonios y referencias de los protagonistas, a través de sesiones de visionado y etiquetado colectivo.

> Difundir las obras rescatadas, publicándolos en internet bajo el tipo de licencia abierta que decidan sus propietarios.

La Digitalizadora de la Memoria Colectiva presenta tres innovaciones respecto a otros proyectos de archivo en Andalucía:

1. La conservación de los documentos audiovisuales es el principio y no el final del camino, como es habitual. Estas obras son la excusa para emprender la tarea de recopilar testimonios en primera persona sobre los acontecimientos que aparecen en ellas y que son parte de nuestra Historia reciente. El momento es ahora o perderemos la posibilidad de contar con la memoria de sus protagonistas.

2. La ciudadanía es un agente activo y no un usuario final. Su memoria, trabajo voluntario y red de contactos es el motor para la localización de estos documentos audiovisuales tan valiosos.

3. El tipo de documentos que nos interesan están en la sombra y no son prioritarios para ninguna institución cultural ni televisión pública. A pesar de su valor, se trata de documentos que presentan unas mayores dificultades de conservación.

Esta orientación innovadora permite generar en la red un entorno de confianza y horizontal donde cada agente se beneficia de las capacidades de los otros socios:

$>$ Los propietarios de los documentos encuentran un cauce para digitalizar y difundir su legado de forma gratuita manteniendo el control sobre su colección audiovisual. 
_a debate Hacia una nueva institucionalidad cultural. Modelos emergentes de gestión...

| coordina Jesús Carrillo Castillo

$>$ Las instituciones se benefician de la calidad y profundidad de una investigación y un proceso de descripción archivística liderado por los propios colectivos.

$>$ Los profesionales de los Archivos y los audiovisuales reciben la recompensa intangible de contribuir con sus conocimientos a un fin de interés general para la sociedad y acorde con sus códigos deontológicos.

Los materiales rescatados, descritos y etiquetados se están comenzando a subir a la página web. No obstante, dicha web no estará abierta al público hasta no contar con una cantidad relevante de documentos digitalizados y tener garantizada la continuidad de la iniciativa.

En septiembre de 2020 arrancamos un ilusionante proyecto de recuperación de la memoria ciudadana en el barrio sevillano de San Diego, financiado por el Instituto de la Cultura y las Artes de Sevilla, junto a vecinos del barrio. Tres meses después se presentarán los resultados de nuestra investigación participativa en los muros y las calles del barrio.

Simultáneamente, está previsto un proyecto de dinamización de una red ciudadana de colaboradores para la descripción del fondo de TeleAntequera, recientemente digitalizado por el Archivo Histórico Municipal de Antequera (Málaga). La experiencia quiere servir de prototipo para futuros procesos de descripción ciudadana. Conjuntamente con responsables del Archivo realizaremos una selección de las obras más relevantes para diseñar eventos de descripción colectiva a los que se invitará a colaborar a vecinos de Antequera.

Los miembros de La Digitalizadora coinciden en:

> El amor a la memoria audiovisual.

$>$ El interés por la mirada de los movimientos sociales y la conciencia de que aportan una valiosa fuente de investigación histórica.
$>$ Las ganas de crear espacios en los Archivos públicos donde se desarrollen procesos de colaboración con la ciudadanía, desde el reconocimiento de su capacidad para generar riqueza y valor.

$>$ El reconocimiento a una necesidad real y urgente. 